\title{
Bariatric single incision laparoscopic surgery - review of initial experience
}

\author{
Maciej Bobowicz, Maciej Michalik, Michał Orłowski, Agata Frask \\ General and Vascular Surgery Department, Ceynowa Hospital, Wejherowo, Poland
}

Videosurgery and other miniinvasive techniques 2011; 6 (1): 48-52 DOI: 10.5114/wiitm.2011.20994

\begin{abstract}
The aim of this review was to assess the results of published experience with bariatric SILS surgery, with a particular focus on treatment feasibility and safety. An EMBASE and MEDLINE database search was performed identifying 13 articles totalling 87 patients in the laparoscopic adjustable gastric banding (LAGB) group, 10 patients in the laparoscopic sleeve gastrectomy (LSG) group, and 1 patient in the Roux-en-Y SILS group. In most series the learning curve was steep and operating times halved with time, reaching $53 \mathrm{~min}$ for LAGB and $90 \mathrm{~min}$ for LSG. In single case reports using strict selection criteria patients were discharged up to 24 hours following surgery. Treatment safety was satisfactory. Only two studies reported some minor complications with rates of up to 9.8\%, including port malposition, port site infection, and seroma or haematoma formation. There were no complications in other studies. LAGB, LSG and Roux-en-Y surgeries were feasible although technically demanding and difficult.
\end{abstract}

Key words: laparoendoscopic single site surgery, obesity treatment, bariatric surgery, LESS in obesity, literature review.

\section{Introduction}

The primary goal of surgery is to provide the best possible care according to evidence-based medicine. Development of new instruments enables innovative surgeries that result in smaller perioperative trauma and stress response, enabling better and faster healing and recovery. Examples of such approaches are natural orifice transluminal endoscopic surgery (NOTES) and single incision laparoscopic surgery (SILS), also known as laparoendoscopic single site surgery (LESS). Both concepts are associated with minimal trauma during the exploration of the abdominal cavity and leave at most a small scar in the umbilicus. Both concepts are still experimental and long-term outcomes are awaited. Potentially, SILS has fewer limitations when compared with NOTES and the range of current indications for its use is relatively broad. During the last two years, SILS has been investigated in the surgical treatment of cholelithiasis [1, 2], abdominal hernias [3], appendicitis $[4,5]$, benign tumours of the colon [6] and in obesity. In this paper the authors briefly review the current status of bariatric single incision laparoscopic surgery.

\section{Methods}

An EMBASE and MEDLINE database search was performed with compilations of the words: "obesity", "bariatric", "surgery", "treatment", "gastric banding" and "sleeve gastrectomy", and synonyms of single port access surgery (SPA), e.g. "laparoendoscopic single site surgery (LESS)", "single incision laparoscopic surgery (SILS)", "single access site surgery (SAS)", "single port laparoscopy (SPL)", "single site access surgery (SSA)", "single laparoscopic port procedure (SLAPP)", "single laparoscopic incision transabdomi- 
nal surgery (SLIT)”, "one port umbilical surgery (OPUS)", "transumbilical endoscopic surgery (TUES)", "embryonic NOTES (E-NOTES)", and "natural orifice transumbilical surgery (NOTUS)".

\section{Results}

Thirteen articles were identified and reviewed. One, by Teixeira et al. [7], was excluded from the analysis as the presented data on 10 patients was further included by the authors in larger published case series [8]. Seven articles were case reports or series of cases of laparoscopic adjustable gastric banding (LAGB) using one of the SILS techniques (a total of 87 patients) [8-14]. Four articles described 10 cases of laparoscopic sleeve gastrectomies (LSG) using SILS technique [15-18]. There was one article describing single incision transumbilical laparoscopic Roux-en-Y gastric bypass [19].

Most of the studies used strict selection criteria with preoperative abdominal ultrasound examination, BMl in the range of $35-45 \mathrm{~kg} / \mathrm{m}^{2}$, female gender and young age. Ultrasound scans were used to assess liver size (mainly the left lobe) as well as the amount of abdominal visceral fat. Female to male ratio was respectively $67: 20$ and $6: 4$ in LAGB and LSG groups. Age ranged between 21 and 62 years. Body mass index (BMI) ranged between $32 \mathrm{~kg} / \mathrm{m}^{2}$ and $68 \mathrm{~kg} / \mathrm{m}^{2}$. The LSG group comprised patients representing slightly higher $B M I$ than the $L A G B$ patients. Group characteristics for SILS LAGB and LSG are shown in Tables I and II respectively.

\section{Access}

Particular investigators used different locations of the access ports and different skin incisions (Tables III

Table I. Characteristics of patients in LAGB group

\begin{tabular}{|lccc|}
\hline Reference & $\begin{array}{c}\text { No. of patients } \\
\text { (gender ratio) }\end{array}$ & $\begin{array}{c}\text { Mean } \\
\text { age }\end{array}$ & $\begin{array}{c}\text { Mean BMI } \\
{\left[\mathrm{kg} / \mathrm{m}^{2}\right]}\end{array}$ \\
\hline Kim et al. [9] & $51(35 \mathrm{~F}:$ 16M) & 33 & 40 \\
\hline Teixeira et al. [8] & $22(20 \mathrm{~F}:$ 2M) & 42 & 42 \\
\hline Saber et al. [13] & $8(7 \mathrm{~F}: 1 \mathrm{M})$ & 49 & 39 \\
\hline Tacchino et al. [14] & $3 \mathrm{~F}$ & 30 & 41 \\
\hline Nguyen et al. [11] & $1 \mathrm{~F}$ & 38 & 39 \\
\hline Oltman et al. [12] & $1 \mathrm{M}$ & 30 & 48 \\
\hline De la Torre et al. [10] & $1 \mathrm{~F}$ & 40 & 41 \\
\hline
\end{tabular}

and IV). The most frequent site of incision was the periumbilical area as it leaves a barely visible scar and provides the best cosmetic effect $[8-10,15,16]$. Another frequently used location was the midpoint in the midline between the xiphoid process and umbilicus $[11,17]$. Access in the midpoint of the midline with a vertical incision adds to the safety of the procedure, although it misses the cosmetic benefit from SILS. Oltman et al. used a left subcostal incision for port placement [12]. The incision length varied between $1.2 \mathrm{~cm}$ and $8.5 \mathrm{~cm}$ [8-18]. A subcostal incision, especially $8.5 \mathrm{~cm}$ long, certainly does not add to the cosmetic effect and many surgeons would consider it a minilaparotomy due to not fulfilling all criteria of SILS surgery.

Two different approaches of accessing the peritoneal cavity were used in particular series. Some authors utilised a TriPort Access System (ACS, Olympus) $[14,18]$ whereas others used multiple standard low profile ports.

\section{Outcomes}

The operating times varied. As expected, the first performed SILS cases using both LAGB and LSG necessitated relatively long operating times of 196 [9] and 177 minutes [15], respectively. In most series the learning curve was steep and operating times halved with time, reaching $53 \mathrm{~min}$ for LAGB [11] and $90 \mathrm{~min}$ for LSG $[15,16]$. The hospitalisation period was usually short. In single case reports using strict selection criteria patients were discharged up to 24 hours following surgery [8, 10-14].

Postoperative pain score reduction compared with multiport laparoscopy is believed to be one of the advantages of LESS. As most of the studies were 'feasibility studies' they did not formally assess postoperative pain. Nevertheless, one study reported decreased opioid analgesics use in the postoperative period [7].

Table II. Characteristics of patients in LSG group

\begin{tabular}{|lccc|}
\hline Reference & $\begin{array}{c}\text { No. of patients } \\
\text { (gender ratio) }\end{array}$ & $\begin{array}{c}\text { Mean } \\
\text { age }\end{array}$ & $\begin{array}{c}\text { Mean BMI } \\
{\left[\mathrm{kg} / \mathrm{m}^{2}\right]}\end{array}$ \\
\hline Saber et al. [15] & $7(4 \mathrm{~F} \mathrm{:} \mathrm{3M)}$ & 46 & 53.5 \\
\hline Nguyen et al. [16] & $1 \mathrm{~F}$ & 53 & 41 \\
\hline Reavis et al. [17] & $1 \mathrm{M}$ & 54 & 38 \\
\hline Amezquita et al. [18] & $1 \mathrm{~F}$ & 39 & 36 \\
\hline
\end{tabular}



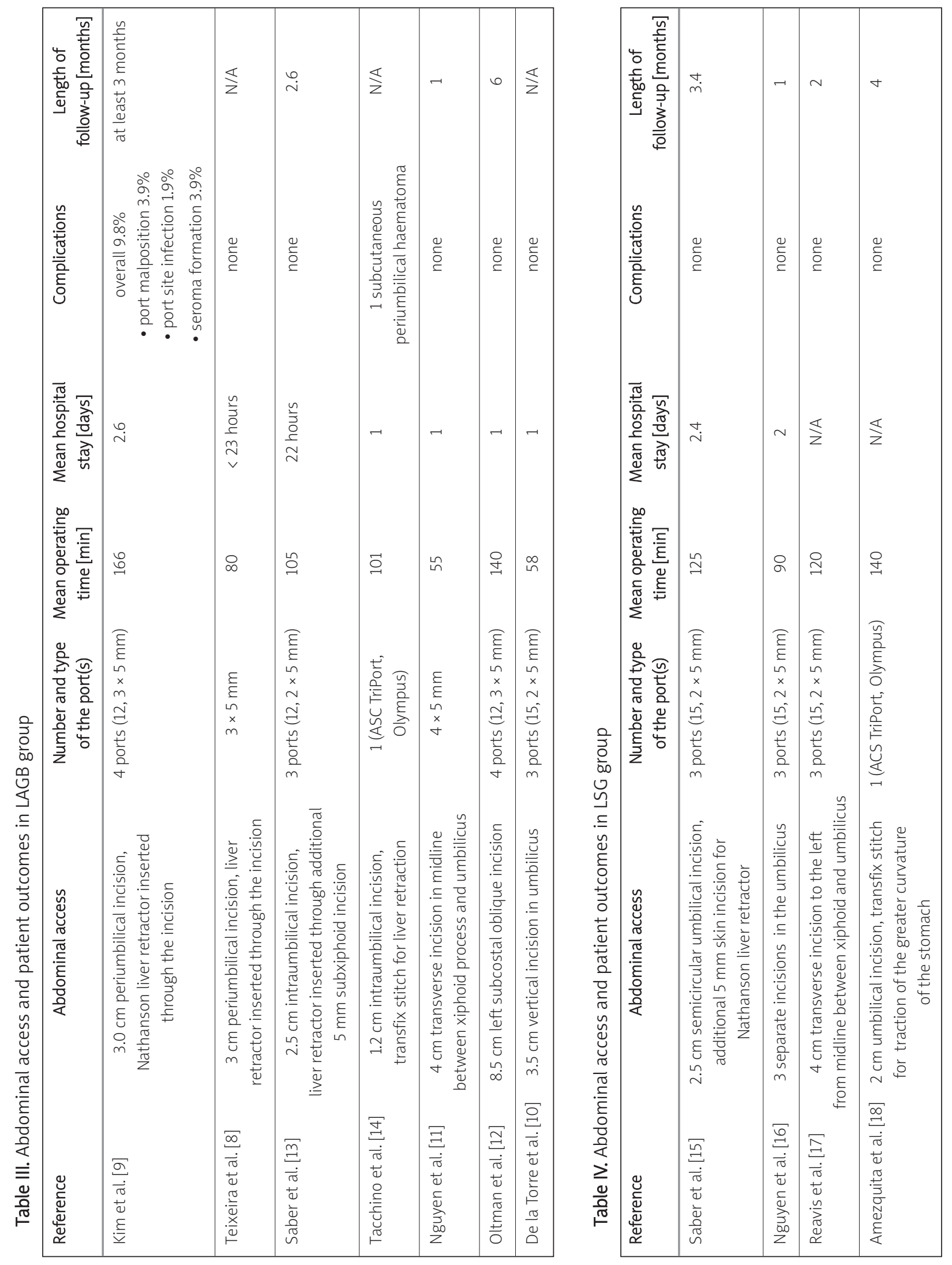


\section{Technical difficulties}

Three studies suggested that placement of additional ports may be required in cases of significant hepatomegaly and air leak from the port sites [8], to enable creation of the retrogastric tunnel [13] or for facilitation of bleeding management [15]. Additionally, in some patients additional skin incisions (without ports) may be necessary for liver retractor insertion [13]. Some authors used other techniques for liver support, such as suspending stitches or tapes passing through the skin and abdominal wall [10, 14], or inserting the liver retractor directly through the periumbilical incision [8, 9]. Amezquita et al. used a transfix stitch for traction of the greater curvature of the stomach [18]. In most LAGB surgeries an adjustable port of the band was placed in the near proximity of the umbilicus [13].

\section{Complications}

All but two studies reported no complications. One study reported complication rates as high as $9.8 \%$ (5 out of 51 patients) [9]. These complications were classified as minor though, and included port malposition, port site infection and seroma formation. These results are comparable with multiport LAGB reports [20-22]. In the study by Tacchino et al. in 1 in 3 patients subcutaneous periumbilical haematoma appeared, which later resolved spontaneously [14].

\section{Follow-up}

In all studies the follow-up periods have been short and data on efficacy are lacking. BMI reduction was reported only in 3 studies with slightly longer than average follow-ups. BMI was reduced from 54 to $46 \mathrm{~kg} / \mathrm{m}^{2}$ during 3.4 months of follow-up in the LSG group [15] from $39 \mathrm{~kg} / \mathrm{m}^{2}$ to $35.5 \mathrm{~kg} / \mathrm{m}^{2}$ in 2.6 months in the LAGB group [13] and from $36 \mathrm{~kg} / \mathrm{m}^{2}$ to $22 \mathrm{~kg} / \mathrm{m}^{2}$ in 4 months [18].

\section{RouX-en-Y}

The only report on a single incision transumbilical laparoscopic Roux-en-Y gastric bypass [19] by Huang et al. also proved its feasibility with reasonable operating time of 170 min with no postoperative complications. The authors used an omega-shaped periumbilical incision with three low profile ports $(1 \times 15 \mathrm{~mm}$, $2 \times 5 \mathrm{~mm}$ ) and liver suspension tape. The 53-year-old female patient with preoperative BMI of $36 \mathrm{~kg} / \mathrm{m}^{2}$ was discharged on the $2^{\text {nd }}$ postoperative day with standard postoperative care.

\section{Discussion}

Technical development has allowed improvement in surgical instruments and progress in modern surgery, which has become rapid in recent years. New generations of equipment continuously emerge, which increases the feasibility of novel methods. Currently, several operative techniques almost do not leave a scar and produce minimal trauma; of these NOTES and SILS are among the most promising procedures. Currently multiple concepts of single access surgery use several acronyms for the same simple concept [23]. The idea is to make just one incision in the umbilicus, the "natural scar" of the human body. Currently these new instruments and concepts are starting to be utilized to address the $21^{\text {st }}$ century's epidemic of obesity. There are however several challenges for LESS/SILS/SPA operations in surgical treatment of obesity [24]. First, they are still experimental methods with unknown long-term efficacy and risk of complications, so ethics committee approval and patient consent should be mandatory. Second, these techniques may prove relatively difficult, as reported by Huang et al. in their article [9]. All single access operations require good laparoscopic operative skills and do not provide good triangulation and fulcrum compared to standard laparoscopy. All instruments are in line, and good traction and range of movement require special articulated instruments; hence appropriate surgical skills are of paramount importance. Third, most bariatric interventions are considered complex and technically demanding.

In conclusion, initial experience from numerous centres in SILS bariatric surgery is encouraging. The results are comparable to reported laparoscopic series. LAGB and LSG performed through single access surgery are feasible and safe in short-term follow-up, with acceptable complication rates. Larger studies focusing on patient safety, improving pain scores and long-term results are warranted for a thorough assessment of these techniques.

\section{References}

1. Michalik M, Frask A, Trybull A, et al. Methods of treatment for gallbladder disease. Videosurgery and other miniinvasive techniques 2009; 4: 121-5. 
2. Kurpiewski W, Pesta W, Kowalczyk M, et al. SILS cholecystectomy - our first experiences. Videosurgery and other miniinvasive techniques 2009; 4: 91-4.

3. Smietanski M, Kitowski J, Tarasiuk D. Laparoscopic abdominal hernia repair with SILS ${ }^{\circledR}$ port - our first experiences. Videosurgery and other miniinvasive techniques 2009; 4: 76-8.

4. Saber AA, Elgamal MH, El-Ghazaly TH, et al. Simple technique for single incision transumbilical laparoscopic appendectomy. Int J Surg 2010; 8: 128-30.

5. Chow A, Purkayastha S, Paraskeva P. Appendicectomy and cholecystectomy using single-incision laparoscopic surgery (SILS): the first UK experience. Surg Innov 2009; 16: 211-7.

6. Bucher P, Pugin F, Morel P. Transumbilical single incision laparoscopic sigmoidectomy for benign disease. Colorectal Dis 2010; 12: 61-5.

7. Teixeira J, McGill K, Binenbaum S, Forrester G. Laparoscopic single-site surgery for placement of an adjustable gastric band: initial experience. Surg Endosc 2009; 23: 1409-14.

8. Teixeira J, McGill K, Koshy N, et al. Laparoscopic single-site surgery for placement of an adjustable gastric band - a series of 22 cases. Surg Obes Relat Dis 2010; 6: 41-5.

9. Kim E, Kim D, Lee S, Lee H. Minimal-scar laparoscopic adjustable gastric banding (LAGB). Obes Surg 2009; 19: 500-3.

10. de la Torre RA, Satgunam S, Morales MP, et al. Transumbilical single-port laparoscopic adjustable gastric band placement with liver suture retractor. Obes Surg 2009; 19: 1707-10.

11. Nguyen NT, Hinojosa MW, Smith BR, Reavis KM. Single laparoscopic incision transabdominal (SLIT) surgery-adjustable gastric banding: a novel minimally invasive surgical approach. Obes Surg 2008; 18: 1628-31.

12. Oltmann SC, Rivas H, Varela E, et al. Single-incision laparoscopic surgery: case report of SILS adjustable gastric banding. Surg Obes Relat Dis 2009; 5: 362-4.

13. Saber AA, El-Ghazaly TH. Early experience with single-access transumbilical adjustable gastric banding. Obes Surg 2009; 19: 1442-6.

14. Tacchino RM, Greco F, Matera D. Laparoscopic gastric banding without visible scar: a short series with intraumbilical SILS. Obes Surg 2010; 20: 236-9.

15. Saber AA, Elgamal MH, Itawi EA, Rao AJ. Single incision laparoscopic sleeve gastrectomy (SILS): a novel technique. Obes Surg 2008; 18: 1338-42.

16. Nguyen NT, Reavis KM, Hinojosa MW, et al. Laparoscopic transumbilical sleeve gastrectomy without visible abdominal scars. Surg Obes Relat Dis 2009; 5: 275-7.

17. Reavis KM, Hinojosa MW, Smith BR, Nguyen NT. Single-laparoscopic incision transabdominal surgery sleeve gastrectomy. Obes Surg 2008; 18: 1492-4.

18. Amezquita FA, Elisa Prada Ascencio N, Gomez D, Torres A. Transumbilical sleeve gastrectomy. Obes Surg 2010; 20: 232-5.

19. Huang CK, Houng JY, Chiang CJ, et al. Single incision transumbilical laparoscopic Roux-en-Y gastric bypass: a first case report. Obes Surg 2009; 19: 1711-5.

20. Mittermair RP, Weiss H, Nehoda H, Kirchmayr W, Aigner F. Laparoscopic Swedish Adjustable Gastric Banding: 6-year Follow-up and Comparison to other Laparoscopic Bariatric Procedures. Obes Surg 2003; 13: 412-7.
21. Cadiere GB, Himpens F, Hainaux B, et al. Laparoscopic Adjustable Gastric Banding. Semin Laparosc Surg 2002; 9: 105-14.

22. Parikh MS, Fielding GA, Ren CJ. U.S. experience with 749 laparoscopic adjustable gastric bands - Intermediate outcomes. Surg Endosc 2005; 19: 1631-5.

23. Zhu JF. Which term is better: SILS, SPA, LESS, E-NOTES, or TUES? Surg Endosc 2009; 23: 1164-5.

24. Romanelli JR, Earle DB. Single-port laparoscopic surgery: an overview. Surg Endosc 2009; 23: 1419-27. 